\section{Early English Railways}

Ix is known that in the archives of various foreign countries there are documents of interest to students of the history of technology ; but seldom is any of this material published. One such document, however, has recently formed the subject of a paper by Mr. P. Zabarinskiy published in vol. 4 of the "Archives for the History of Science and Technology". The paper itself is in Russian, but with it is the letter of William Vaughan dated, London, June 14, 1804, and addressed to his Excellency Vice-Admiral Chichagoff, minister of the marine at St. Petersburgh. William Vaughan (1752-1850) was a director of the Royal Exchange Assurance Corporation, London, and was much interested in canals and railways and docks. Railways, he said, were common in England and Wales for the conveyance of coals, limestone, ore and such things, and in the London Docks, in which he evidently was particularly interested, railroads and waggons were used in the excavations. Experiments were apparently made at the Docks and in one of these, he said, "In six days of 12 hours, 25 men filled, 24 boys drove and 24 horses conveyed, 3650 cubic yards of earth to the distance of 400 yards and returned the waggons empty". Vaughan described clearly the turntables used on the banks of the Thames, gave estimates of the cost of removing material and made some remarks on the use of railways in Russia.

\section{Work of the Rockefeller Foundation}

THE Rockefeller Foundation's report for 1933 presents a tale of vast and varied activities, for the financing of which it had, in pursuance of its mission "to aid in the process of the rationalisation of life", made itself wholly or partially responsible. Its policy in relation to the pressing social problems of the day is guided by the principle that it "can neither remain indifferent to them nor relinquish the support of the fundamentals on which in the long run the control of man's destiny depends". In medical and natural sciences, emphasis has been laid on the problem of mental health and the advancement of the rapidly evolving modern science of man; in the social sciences, on the problem of economic structure and process, international relations and community organisation and planning; and in the humanities, on the encouragement of international cultural understanding and the preservation and interpretation of American culture. Early in the year a sum of a million and a half dollars was set aside for emergency grants for work in connexion with the 'new deal' programmes. Contributions were also made as an emergency measure towards the salaries of eminent scholars displaced for political reasons in Europe and 'adopted' by universities in Europe and the United States. Appropriations during the year totalled about ten million dollars. Among the larger appropriations in the field of the social sciences were: Brookings Institution for Economic Studies, 250,000 dollars; Institute of Economic and Social Research, Paris, 350,000 dollars ; League of Nations, 275,000 dollars; National Bureau of Economic
Research, New York, 225,000 dollars; social science research aids, 150,000 dollars; Social Science Research Council, New York City, 265,000 dollars.

\section{Scientific Horticulture}

THE third Year-book of the Horticultural Education Association appears under the new title "Scientific Horticulture". It is longer than in previous years, its contents cover a wider field, and go far to justify the change of heading. The presidential address of the Association is by Dr. T. Wallace, and deals with "Science and Fruit-growing", mainly from a historical point of view. Many of the papers in the volume were delivered at a revision course in horticulture arranged by the University of Reading in September, 1934. The practical nature of the lectures of this course is at once apparent-they deal with the highest-grade modern processes in vegetable culture, glasshouse work and bulb-growing, together with descriptions of diseases and pests. They are incorporated as Bulletin 47 of the University of Reading. Articles contributed specially for the year-book include "Commercial Horticulture in Northern Ireland" by W. J. Megaw and E. E. Skillman, "Fruittree Spraying Equipment" by J. Turnbull, "The R.H.S. Apple and Pear Conference, 1934" by N. B. Bagenal and R. T. Pearl, "Selection of Soils for Dessert Apple Growing" by B. S. Furneaux, "Twentyone Years' Fruit Research at East Malling" by R. T. Pearl and R. Hart", "Waste Products in Horticulture, their Utilisation as Humus" by Sir Alfred Howard, and "Research at Rothamsted of Importance in Horticulture" by Miss M. D. Glynne and H. V. Garner. The volume entirely justifies its name, and is a great credit to Mr. R. T. Pearl, its honorary editor. One has the feeling, however, that the bias is on the practical side, and that the newer scientific principles which most gardeners have yet to learnsuch as photoperiod, seed stratification and control, plant sterility and the conditions affecting vegetative regeneration-are not expounded. The school garden, the primary stage in horticultural education, receives no notice whatever.

\section{Over-population in America's Deer Herds}

Is the Yellowstone National Park, the two great herds of wapati or 'elk' now comprise about 30,000 individuals, and in the northern area the droughtreduced pastures have accentuated a long-standing problem of over-population (Science Service, Washington, D.C.). The fundamental cause of the food scarcity which has resulted is the inevitable restriction of the natural emigrations of the herds, for outside the northern boundary of the Park, the Yellowstone Valley is occupied by cattle ranches. These make an impassable barrier and confine the deer permanently to a quite inadequate portion of what is naturally only their winter range. Overgrazing has altered the vegetation for the worse; most of the nutritious native grasses have been killed out, and their place taken by a weed grass, fox-tail, which apart from its low nutritive value, pierces the gums and permits the growth of a fungus 
producing the disease of 'lump-jaw'. Two solutions have been proposed : one that about half the total number of deer should be captured, transferred to a central slaughtering station outside the Park, and killed and distributed to destitute Indians ; the other that the captured animals should be set free in areas of Montana where they could be hunted by sportsmen. The second plan is that favoured by National Park officers, but they insist that whatever plan is adopted, it must be carried out promptly, because of the daily increasing seriousness of the emergeney.

\section{Meteorology in India}

THE report on the administration of the Meteorological Department of the Government of India in 1933-34 has for frontispiece a very good photograph of a tornado which visited Peshawar on April 5, 1933, probably the first photograph to be obtained of this phenomenon in India. The Department has again been hampered by the heavy curtailment of expenditure initiated in 1932, and has nevertheless had to face increased demands for meteorological informa. tion on the part of air mail services. It was necessary, therefore, simply to dispense with additional forecasting centres and other facilities demanded by the circumstances, and to carry on with what is described as a skeletal meteorological organisation along each air route. Between April 1, 1933 and March 31, 1934, nearly six thousand weather reports and forecasts were issued to aviators by the departmental forecasting centres at Karachi, Calcutta and Poona and the Royal Air Force centres at Quetta and Peshawar, which are under the technical though not the administrative control of the Department. The report quotes remarks made in a discussion at the Royal Geographical Society of an account of the Ruttledge Mount Fverest Expedition that are a strong tribute to the help that can be given to mountain expeditions by local forecasting centres in India. In this case, the Expedition was in touch with Dr. Sen of the Calcutta office for the supply of special forecasts. Scepticism of the value of forecasts that are based largely on observing stations at a comparatively low level was quickly seen to be unjustified, particularly when an abnormally early monsoon was successfully predicted. Among the many activities of the Department, it may be noted that the recently established branch of agricultural meteorology carried on special researches into matters affecting the growth of crops, and that some of the results have already been published.

\section{The Engineer as Planner}

IN an article entitled "The Engineer as Planner" reprinted by Engineering Inspection of January 1935, Dr. Victor Cofman emphasises the fact that the important factor in the solution of economic and social problems is the application of the spirit and methods of engineering and science to the wider field of human relations, not the particular person who does it. While everyone agrees that the planning of production is the obvious duty of the engineer, opinions are divided as to how far the engineer can help in the social and economic fields, and it is often pointed out that eminent engineers and men of science do not show particular perspicacity or vision when dealing with social problems. It is essential that those who will have to consider social questions must have a full knowledge of the pertinent facts, and it may be necessary under existing conditions to have a team consisting of sociologists and economists, practical men acquainted with the problems, working together with engineers and men of science acquainted with the methods of science. The opponents of planning take it for granted that planning is synonymous with greater restriction upon individual freedom, but one may plan for freedom and peace just as one may plan for oppression and war. The true opposition is not between planning and liberty, but between arbitrary interference and liberty.

\section{Bibliography of Seismology}

THE last quarterly number of this useful work, which is edited by Mr. E. A. Hodgson and published by the Dominion Observatory, Ottawa, completes the twelfth volume and the list of memoirs for 1934 . The total number of memoirs referred to during the year is 506, some of them in title only, but many of the more important accompanied by a brief abstract. It is satisfactory to notice that the number of collaborators is increasing, and that new countries are being added to the list, though there is still no representative for Great Britain. The subject-index for the year under more than fifty headings adds greatly to the value of the Bibliography.

\section{The Planetarium}

AcCording to an article in The Times of June 22, accommodation for a planetarium is being included in the plans for rebuilding the centre portion of the Science Museum, South Kensington. It is stated that Germany already has thirteen planetaria, America four, Italy two and Holland, Sweden, Austria and the U.S.S.R. one each. Such an instrument enables celestial bodies to be shown as bright objects on the inside of a large darkened dome, and by means of elaborate mechanism their movements can be demonstrated. The method thus marks a great advance on the orrery, in which the positions and movements of bodies in the solar system are represented in a mechanical model. It will be recalled that the first Zeiss planetarium, erected at Munich, was described and illustrated in NaTURE of December 27, 1924, p. 937.

\section{Astronomical Phenomena during July}

VENUS is a conspicuous object in the evening sky. The planet reaches its greatest eastern elongation on June 30 , when the stellar magnitude is $-4 \cdot 0^{\mathrm{m}}$, but the planet will continue to increase in brilliance throughout July, the stellar magnitude being $-4 \cdot 2^{\mathrm{m}}$ on July 31. As both Mars and Jupiter are conspicuous in the evening sky, one can get a very good idea of the ecliptic stretching across the sky, especially 